\title{
The Development of Cooperative Learning Using Jigsaw Activities for Learning Achievement and Self-directed Learning Behaviors of Master Nursing Students
}

\author{
Charuwan Kritpracha, Wipa Sae-Sia, Orawan Nukaew, Piyanuch Jittanoon, Sopen Chunuan, and Ophat \\ Kaosaiyaporn
}

\begin{abstract}
The purposes of this research were to 1) develop cooperative learning using jigsaw activities to improve learning achievement and self-directed learning behaviors of master nursing students, and 2) test the effectiveness of the cooperative learning using jigsaw activities.

The findings revealed the following information:

1. Cooperative learning using jigsaw activities was developed. The jigsaw learning activities were divided into 6 steps; Step 1: Introduce cooperative learning using jigsaw activities, Step 2: Assign students to expert groups and learning groups, of which each student was assigned to be in an expert group for certain topics and learning groups for other topics, Step 3: The students in the expert groups cooperate with each other, study and share knowledge, Step 4: The students in the expert groups return to their learning groups, Step 5: The students in the learning groups cooperate with each other, with expert peer facilitation, and Step 6: Evaluation.

2. After participating in the activities, there was a statistically significant increase in learning achievement scores $(p<.01)$ and self-directed learning scores $(\mathbf{p}<.01)$.

This study affirms that the cooperative learning using jigsaw activities improve students' learning achievement and self-directed learning behaviors.
\end{abstract}

Index Terms-Jigsaw activities, learning achievement, self-directed learning.

\section{INTRODUCTION}

The course of statistics for nurses is the core course in Master of Nursing Science Program, Faculty of Nursing, Prince of Songkla University, Thailand. This 16-week course is provided for master nursing students in 5 programs, with 4 programs for Thai students, namely adult nursing 1 (6 students), adult nursing 2 (10 students), psychiatric nursing (6 students), obstetrics/gynecological nursing (11 students), and 1 international program (12 students). The course is to enhance students to achieve competency of essential knowledge of statistics, analyzing data using descriptive statistics and inferential statistics, application of computer software in processing and analyzing data, interpretation and presentation of statistical analysis. Competency gained from the course will benefit the students in conducting a research study, and utilizing results from an existing research study in

Manuscript received November 29, 2017; revised January 10, 2018. The research grant was supported by Faculty of Nursing, Prince of Songkla University.

The authors are with Prince of Songkla University, Thailand (Corresponding author: Charuwan Kritpracha; e-mail: charuwan.kr@psu.ac.th). an efficient manner.

The course of statistics for nurses is a compulsory course and accepted to be beneficial for students; however, the achievement was not satisfactory. The students of the course, both Thai and International students, provided feedback that the course was very useful, particularly in conducting their thesis research study and future research study. However, the content is difficult to understand. In the past 3 academic years, students' learning achievement of the course of statistics for nurses was not satisfactory, with $69.57 \%, 34.07 \%$, and $44.61 \%$ of students who registered for the course for the academic years of 2012, 2013, and 2014, respectively, receiving scores less than the minimum requirement.

In addition, students' characteristics including self-directed learning behaviors contribute to students' learning achievement [1]. Traditional learning activities in the course were provided through lectures and exercises. Teaching materials included lesson content or worksheets, posted on Learning Management System. Learning activities to exalt students' self-directed learning behaviors are, therefore, vital to be established. Especially as students in 21 st century, they are expected to be self-directed and ultimately cultivated to be lifelong learners.

Researchers were interested in developing a teaching and learning model to improve students' learning achievement and self-directed learning behaviors by using cooperative learning using jigsaw activities. Cooperative learning is a type of instructional method that students will learn by working together actively and collaboratively in a small group [2]. The students may have different abilities and will engage in the activities together to achieve a common goal. The students learn together, help each other, cooperate in a group and share responsibility. The cooperative learning is based on student-centered learning. Existing research has supported the contribution of cooperative learning in facilitating students' achievement [3]-[5].

Jigsaw activity is a grouping approach in which members of the class are organized into two groups, an expert group and a learning group. Jigsaw activity is an influential strategy to support students to become active and self-directed in their learning, facilitate sharing information with others, minimize burden time, and be individually accountable for their learning. According to previous research studies, jigsaw activity helps students to learn, acquire knowledge, understand better and improve student's learning behaviors [6], [7].

Therefore, to enhance master nursing students' learning 
achievement and self-directed learning behaviors, the researchers conducted a classroom action research to develop a model of cooperative learning using jigsaw activities for the course of statistics for nurses. Furthermore, the effectiveness of the model was also examined.

\section{THE PURPOSES OF THE STUDY}

1) To develop cooperative learning using jigsaw activities to improve learning achievement and self-directed learning behaviors of master nursing students.

2) To test the effectiveness of the cooperative learning using jigsaw activities.

\section{HYPOTHESIS}

Master nursing students have a higher learning achievement and higher self-directed learning behaviors after participating in cooperative learning using jigsaw activities on the statistics for nurses course at the statistical significance of $\mathrm{p}<.05$.

\section{RESEARCH METHODOLOGY}

A. Population and Sample

1) Population was master nursing students, Prince of Songkla University, Thailand

2) The sample consisted of 45 master nursing students, who registered for the statistics for nurses course in academic year 2015 .

\section{B. Research Design}

This classroom action research was conducted to develop cooperative learning using jigsaw activities to improve students' learning achievement and self-directed learning behaviors of master nursing students. The process of this research study is illustrated in Fig. 1 and described as follows:

1) Analyzing and synthesizing related literature and documents regarding the teaching and learning models and strategies to improve students' learning achievement and self-directed learning behaviors.

2) Developing the cooperative learning using jigsaw activities to improve students' learning achievement and self-directed learning behaviors of master nursing students. Afterwards, the developed cooperative learning using jigsaw activities was discussed in a focus group of the course instructors, and validated by 3 experts whose expertise is in teaching and learning.

The cooperative learning using jigsaw activities to improve learning achievement and self-directed learning behaviors of master nursing students consists of 6 steps as follows:

Step 1: Introduce cooperative learning using jigsaw activities as follows;

- Explain learning objectives and topics of the course

- Introduce details of cooperative learning using jigsaw activities

- Elaborate responsibilities of expert groups and learning groups.
- Determine timing in group work

- Introduce learning tools

- Clarify task assignments and responsibilities of expert groups and learning groups.

- Explain learning facilitation

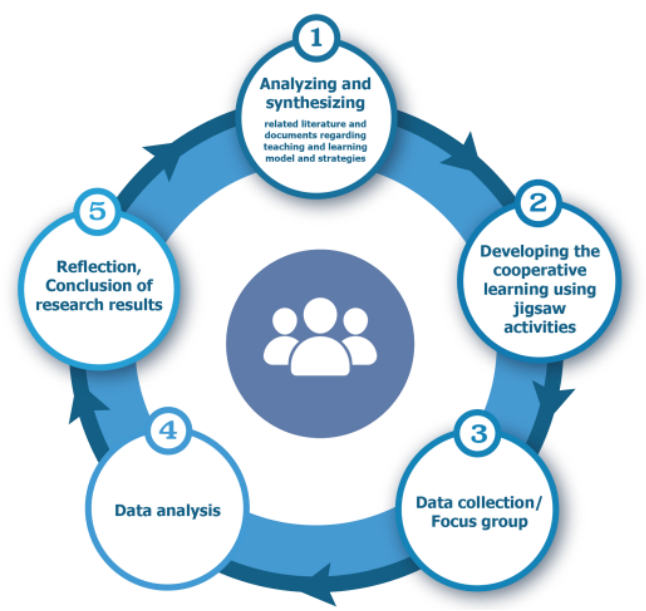

Fig. 1. The process of research study.

Step 2: Assign students to expert groups and learning groups, of which each student was assigned to be in an expert group for certain topics and learning groups for other topics.

In this step, the students were divided into small groups with $4-6$ students per group, called "learning groups." Each student was assigned $1-2$ topics in which they would become expert. Learning groups comprised heterogeneous members according to previous grade point average, gender, to enhance cooperative learning.

Step 3: The students in the expert groups cooperate with each other, study and share knowledge

The students who were assigned the same topic formed a group called "expert group." The students in the expert group for the topic, then, cooperated within the group to study material facilitated by instructors, searched for additional material as needed, studied together, discussed, and shared their findings with each other.

Step 4: The students in expert groups returned to their learning groups.

After peer cooperating within the expert groups, the students in the expert group for the topic returned to their learning groups and shared what they had learned and facilitated peer learning.

Step 5: The students in the learning groups cooperated with each other, studied and shared knowledge with peer facilitation from students in the expert groups of the topic.

With cooperative learning using jigsaw activities, every student acted as expert in certain topics and learned from others in other topics, cooperated with each other and learned, resulting in the whole jigsaw puzzle being completed.

Step 6: Evaluation. After cooperative learning using jigsaw activities, the evaluation is conducted through exercises and taking the exam.

3) Data collection and focus group

- Ethical consideration

This study was approved by the Institutional Research Board of the Faculty of Nursing, Prince of Songkla University, Thailand. 
- The researchers asked a graduate study office staff member to collect a list of master nursing students at Faculty of Nursing, Prince of Songkla University, who enrolled in statistics for nurses course in semester 1 of academic year 2015. The eligible students' permission was requested for the researchers to approach.

- The researchers informed all eligible students about this research study. All 45 students voluntarily participated and signed informed consent. Clarification of the research study was conducted, including research objectives, cooperative learning using jigsaw activities that the students would experience, and data collection process. The students were also informed about their right to withdraw anytime without any negative consequences.

- Before joining the cooperative learning using jigsaw activities, the students were asked to complete Participant's Characteristics Questionnaire, Statistics Test, and Self-directed Learning Questionnaire.

The Statistics Test was developed by the researchers. The test consists of 40 multiple-choice questions with correct and incorrect answers. A score of 1 indicates a correct answer, and 0 indicates an incorrect answer. Possible total scores range from $0-40$, with higher scores reflecting higher learning achievement. The Statistics Test was validated by 3 experts whose expertise is in teaching and learning, and statistics in nursing research. The Kuder-Richardson (KR-20) coefficient was examined to determine the internal consistency reliability, yielding a coefficient of .83 .

The Self-directed Learning Questionnaire was developed by the researchers through literature review [8]-[10]. The Questionnaire consists of 50 items on 5-point Likert scale ranging from 1 (the statement is least true for you) to 5 (the statement is absolutely true for you). Possible total scores range from $1-250$, with higher scores reflecting higher self-directed learning behaviors. The Self-directed Learning Questionnaire was validated by 3 experts whose expertise is in teaching and learning. The Cronbach's alpha coefficient was examined to determine the internal consistency reliability, yielding a coefficient of 96 .

- The focus group was conducted at the end of week 16 for reflecting and seeking opinions on cooperative learning using jigsaw activities from the students. Discussion for further improvement was also performed.

4) Data analysis

- The data of participants' characteristics were analyzed using descriptive statistics.

- The data of students' learning achievement and self-directed learning behaviors were analyzed using descriptive statistics.

- Comparison of the differences of students' learning achievement and self-directed learning of students before and after joining cooperative learning using jigsaw activities using paired t-test statistics.

Before performing the analysis, the assumptions of normality and outliers were examined. Normality was checked by examining standardized skewness and standardized kurtosis. The outliers were checked by visual inspection from histogram. The results showed that the assumptions were met.
- The data from focus group was transcribed. The content analysis, then, was conducted.

5) Reflection and conclusion of research results

The researchers established a meeting for reflection and conclusion of the results. Conducting the next cycle of the classroom action research was also planned.

\section{RESEARCH RESULTS}

The samples consisted of 45 master nursing students, who registered in statistics for nurses course in academic year 2015. The results, as shown in Table I, revealed that the majority of the sample were female $(n=40,88.9 \%)$; The majority of ages were around $21-30$ years old $(n=34 ; 75.6 \%)$; most were Buddhist ( $n=30 ; 66.7 \%)$; approximately half of them had experience in conducting a research study $(n=24$; $53.3 \%)$ and the majority had a grade point average from undergraduate study of $3.01-3.50$. Average duration since undergraduate study was 6.02 years $(\mathrm{SD}=4.84)$.

TABLE I: PARTICIPANTS' CHARACTERISTICS $(N=45)$

\begin{tabular}{|c|c|c|}
\hline Participants' characteristics & $\mathrm{n}$ & Percent \\
\hline \multicolumn{3}{|l|}{ Program } \\
\hline Adult nursing 1 & 6 & 13.3 \\
\hline Adult nursing 2 & 10 & 22.2 \\
\hline Psychiatric nursing & 7 & 15.6 \\
\hline $\begin{array}{l}\text { Obstetrics/Gynecological } \\
\text { nursing }\end{array}$ & 12 & 26.7 \\
\hline International program & 10 & 22.2 \\
\hline \multicolumn{3}{|l|}{ Gender } \\
\hline Male & 5 & 11.1 \\
\hline Female & 40 & 88.9 \\
\hline \multicolumn{3}{|l|}{ Age (years) } \\
\hline $21-30$ & 34 & 75.6 \\
\hline $31-35$ & 6 & 13.3 \\
\hline 36 years and up & 5 & 11.1 \\
\hline \multicolumn{3}{|l|}{ Religion } \\
\hline Buddhist & 30 & 66.7 \\
\hline Christian & 1 & 2.2 \\
\hline Muslim & 9 & 20 \\
\hline Hindu & 5 & 11.1 \\
\hline \multicolumn{3}{|l|}{$\begin{array}{l}\text { Experience in conducting } \\
\text { research }\end{array}$} \\
\hline Yes & 24 & 53.3 \\
\hline No & 21 & 46.7 \\
\hline \multicolumn{3}{|l|}{ Undergraduate grade point average } \\
\hline $2.50-3.00$ & 16 & 35.6 \\
\hline $3.01-3.50$ & 20 & 44.4 \\
\hline $3.51-4.00$ & 9 & 20 \\
\hline
\end{tabular}

Table II shows the mean scores and standard deviation of master nursing students' learning achievement and self-directed learning behaviors, and comparisons of the mean scores before and after participating in cooperative learning integrated with Jigsaw activities. The results revealed that the learning achievement scores after the activities were statistically significantly higher than before the activities $(t=16.07, p<.01)$. Moreover, the self-directed learning scores after the activities were statistically significantly higher than before the activities $(t=-3.73, p<.01)$.

Results from focus group provide master nursing students' view of the experience of participating the cooperative learning integrated with Jigsaw activities. The students 
reported an enjoyable experience and positive views as follows:

"Explanation from friends is easy to understand because of similar background and capability. I feel comfortable when I ask friends."

"Learning in small group helps me understand more."

"The advantage is more understanding. Dividing into small group is better. The students can understand clearly and we assist each other. Students in small group are more engaging."

"Learning in small group is good. It can help weak students to get more understanding and increase learning and exam scores."

"Some discussion is more difficult to achieve in large-group discussion. So small group can solve the problem."

"It is fun to talk and discuss with friends, not only sit down and listen to lectures."

"I never think that I am also be able to understand the content by searching knowledge by myself."

"I feel that I learn and understand more when I teach friends."

"I like this activity because I can learn and understand the difficult contents, and also reduce the burden and load of the study."

"The activities are good and interesting"

"These activities are good to help me understand even this statistics course that is very difficult."

"We are closer as friends who learn and help each other."

Positive views were reported. However, few students mentioned negative views:

"Sometimes expert friend from the topic cannot explain to help me understand."

"I am worry that I do not have enough knowledge to explain friends."

TABLE II: COMPARISONS OF MEAN SCORES OF MASTER NURSING STUDENTS' LEARNING ACHIEVEMENT AND SELF-DIRECTED LEARNING BEHAVIORS BEFORE AND AFTER PARTICIPATING THE COOPERATIVE LEARNING USING JIGSAW ACTIVITIES $(N=45)$

\begin{tabular}{|c|c|c|c|c|c|c|}
\hline \multirow{2}{*}{ Variables } & \multicolumn{2}{|c|}{ Before } & \multicolumn{2}{|c|}{ After } & \multirow{2}{*}{$\mathrm{t}$} & \multirow{2}{*}{$\mathrm{p}$} \\
\hline & $\overline{\mathrm{X}}$ & S.D & $\overline{\mathrm{X}}$ & S.D & & \\
\hline $\begin{array}{l}\text { Learning } \\
\text { Achievement }\end{array}$ & 17.87 & 3.87 & 27.27 & 3.31 & -16.07 & .000 \\
\hline $\begin{array}{l}\text { Self-directed } \\
\text { learning } \\
\text { behaviors }\end{array}$ & 188.18 & 18.36 & 196.09 & 20.28 & -3.73 & .001 \\
\hline
\end{tabular}

\section{DISCUSSION}

As hypothesized, master nursing students had a statistically significantly higher learning achievement after participating in cooperative learning using jigsaw activities. The activities offer various benefits for students. Active and cooperative participation in class results in increasing engagement. Peer interaction creates a comfortable learning atmosphere. Moreover, social relationships, bonding, and team work are promoted, and may lead to further learning and networking. Discussion, in particular in small groups, facilitates critical thinking skills. Exposure to different thoughts enhances understanding. Importantly, reducing the load of study benefits students to allow more time to study, and increase motivation. After cooperating with each other on each piece of the jigsaw topic and putting it together, the whole jigsaw of knowledge becomes complete. As a result, learning achievement exalts. The results were consistent with previous studies showing that jigsaw activities enhanced students' performance [2], [11]-[13], improved problem solving skills, communication skills [14], and was as effective as expert instruction for learning achievement. [15]. In addition, a study reported advantage of the jigsaw method in retention of knowledge [16].

As hypothesized, master nursing students had statistically significantly higher self-directed learning after participating in cooperative learning using jigsaw activities. Each student has topics that are his/her responsibility to study as an expert on the topics and share with other students. The expert students need to study and search for additional knowledge. Moreover, achievement from studying by themselves promotes students to sustain self-directed leaning. Confidence in self-directed study also increased.

The results of this study support that cooperative learning using jigsaw activities improve students' learning achievement and self- directed learning behaviors.

\section{RECOMMENDATIONS}

The results confirm advantages of cooperative learning using jigsaw activities. Continuing cycles of this classroom action research is recommended. Furthermore, replication study in students from various disciplines that have different context is also suggested.

\section{REFERENCES}

[1] A. M. Cazan and B. A. Schiopca, "Self-directed learning, personality traits and academic achievement," Procedia-Social and Behavioral Sciences, vol. 127, pp. 640-644, 2014.

[2] N. H. Azmin, "Effect of the jigsaw-based cooperative learning method on student performance in the general certificate of education advanced-level psychology: An exploratory Brunei case study," International Education Studies, vol. 9, no. 1, pp. 91-106, 2016.

[3] R. Prasitkusol, "The effect of jigsaw cooperative of sampling techniques in the course of statistics for research," Phranakhon Rajabhat Research Journal, vol. 10, no. 2, pp. 111-122, 2015.

[4] D. W. Johnson, Learning Together and Alone: Cooperative, Competitive, and Individualistic Learning, 4th ed. University of Minnesota: Prantice-Hall, 1994.

[5] M. A. Gunter, H. E. Thomas, and L. M. Susan, Instruction: A Models Approach, 5th ed. Boston: Pearson Education, 2006.

[6] R. E. Slavin, Cooperative Learning: Theory, Research and Practice, 2nd ed. Boston: Allyn and Bacon, 1995.

[7] F. Pozzi, "Using jigsaw and case study for supporting online collaborative learning," Computers \& Education, vol. 55, no. 1, pp. $67-75,2010$

[8] S. Chareonchim, T. Kantiya, S. Chareonchim, and U. Samakratkit. (2012). Self-directed learning ability of pre-service teachers. Faculty of Education and Development Sciences Kasetsart University. [Online]. Available:

http://www.edu.kps.ku.ac.th/DBresearch/document/DB_RESEARCH /Research30.pdf

[9] P. Ucharattana, T. Augmekiat, A. Khanta, and T. Limpongsathorn, "Effect of clinical teaching methods using portfolio and knowledge market on self-directed learning of students in program of nursing specialty in nursing management," Journal of Nursing Science, vol. 30, no. 4, pp. 18-124, 2012.

[10] B. Padwang and S. Udomluck, "A study of the self-directed learning readiness of nursing students of Boromarajonani College of Nursing, 
Nakorn Lampang," Nursing Journal of the Ministry of Public Health, vol. 21, no. 2, pp. 74- 84, 2011.

[11] J. M. Leyva-Moral and M. R. Camps, "Teaching research methods in nursing using Aronson's jigsaw technique. A cross-sectional survey of student satisfaction," Nurse Education Today, vol. 40, pp.78-83, 2016.

[12] A. Karacop, "The effects of using jigsaw method based on cooperative learning model in the undergraduate science laboratory practices," Universal Journal of Educational Research, vol. 5, no. 3, pp. 420-434, 2017.

[13] G. T. Buhr, M. T. Heflin, H. K. White, and S. O. Pinheiro, "Using the jigsaw cooperative learning method to teach medical students about long-term and postacute care," Journal of the American Medical Directors Association, vol. 15, no. 6, pp. 429-434, 2014.

[14] J. A. Wilson, A. H. Pegram, D. M. Battise, and A. M. Robinson, "Traditional lecture versus jigsaw learning method for teaching medication therapy management (MTM) core elements," Currents in Pharmacy Teaching and Learning, vol. 9, pp. 1151-1159, 2017.

[15] N. Charlier, L. V. D. Stock, and P. Iserbyt, "Peer-assisted learning in cardiopulmonary resuscitation: The jigsaw model," The Journal of Emergency Medicine, vol. 50, no. 1, pp. 67-73, 2016.

[16] O. Sagsoz, O. Karatas, V. Turel, M. Yildiz, and E. Kaya, "Effectiveness of jigsaw learning compared to lecture-based learning in dental education," Journal of American Medical, vol. 21, pp. 28-32, 2017.

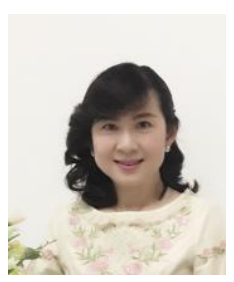

Charuwan Kritpracha pursued the bachelor, master, and doctoral studies in the area of nursing science. Her research studies focus on cognition contributing to behaviors in patients with chronic diseases. Importantly, her research studies also address teaching and learning models to enhance students' learning competency and improve quality of education. Dr. Kritpracha is now a lecturer at Division of Adult and Elderly Nursing, Faculty of Nursing, PSU and serves as vice director of PSU Research Center for Educational Innovations and Teaching and Learning Excellence.

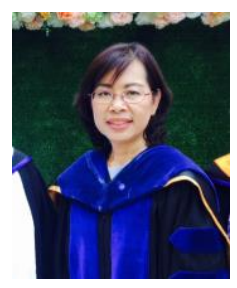

Wipa Sae-Sia is an assistant professor at the Faculty of Nursing, Prince of Songkla University, Thailand. She received a doctor of philosophy in nursing from University of Missouri Columbia, USA. Her research areas are related to wound care and classroom research.

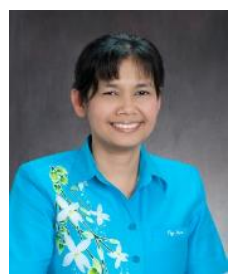

Orawan Nukeaw is an assistant professor at Division of Psychiatric Nursing and Mental Health, Faculty of Nursing, Prince of Songkla University, Thailand. She received her doctoral degree from University of Columbia, the United States. She is an expert in the area of improving nursing care for persons with psychological disorders. She is also interested in conducting classroom research. She is now the head of Division of Psychiatric Nursing and Mental Health, Faculty of Nursing, Prince of Songkla University.

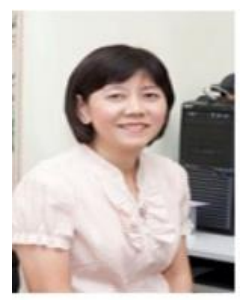

Piyanut Jittanoon is an associate professor at Division of Community Nurse Practitioner, Faculty of Nursing, Prince of Songkla University, Thailand. She completed her bachelor degree from Mahidol University, Thailand. She pursued her Master degree and doctoral degree from Case Western Reserve University, the United States. She is an expert in the area of promoting health behaviors in communities. She was recipient of Excellent Researcher award in the year 2009. She is also interested in conducting research to improve quality of teaching and learning. She is now the head of Division of Community Nurse Practitioner, Faculty of Nursing, Prince of Songkla University.

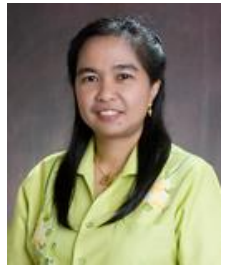

Sopen Chunuan is an assistant professor at the Department of Maternal-Newborn Nursing and Midwifery, Faculty of Nursing, Prince of Songkla University. She received a bachelor of nursing science from Faculty of Nursing, Prince of Songkla University. She received a master of nursing science in Parents and Child Nursing and a doctoral of philosophy of nursing science from the College of Nursing, University of Kentucky, USA. She is the head of the Department of Maternal-Newborn Nursing and Midwifery, Faculty of Nursing, Prince of Songkla University, Thailand.

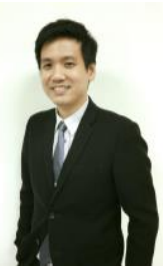

Ophat Kaosaiyaporn is an assistant professor and also the chair of master's program in educational technology and communications at the Department of Educational Technology, Faculty of Education and also the Secretary and Committee Member of the Research Center for Educational Innovations and Teaching and Learning Excellence, Prince of Songkla University, Thailand. He received the B.Ed. in art education and M.Ed. in educational technology and communications from Prince of Songkla University, Thailand, and Ph.D. in Educational Communications and Technology from Chulalongkorn University, Thailand. 